\title{
HETEROGENEOUS FENTON-LIKE OXIDATION OF METHYLENE BLUE USING ALTERNATIVE CATALYSTS
}

\author{
Juraj MICHÁLEK ${ }^{1}$, Kseniya DOMNINA ${ }^{2}$, Veronika KVORKOVÁ ${ }^{1}$, \\ Kristína ŠEFČOVIČOVÁ ${ }^{1}$, Klaudia MONČEKOVÁ ${ }^{1}$, Maroš SOLDÁN ${ }^{1}$ \\ ${ }^{1}$ Slovak University OF TECHNOLOGY IN BRATISLAVA \\ FACULTY OF MATERIALS SCIENCE AND TECHNOLOGY IN TRNAVA \\ INSTITUTE OF INTEGRATED SAFETY \\ Ulica JÁNA BotTu 2781/25, 91724 TRNAVA, SLOVAK REPUBLIC \\ ${ }^{2}$ VOTKINSK BRANCH OF KALASHNIKOV IZHEVSK \\ STATE TECHNICAL UNIVERSITY, RUSSIA \\ e-mail: juraj.michalek@stuba.sk,kseniya_domnina@bk.ru, veronika.kvorkova@stuba.sk, \\ kristina.sefcovicova@stuba.sk, maros.soldan@stuba.sk \\ Received 23 April 2021, Accepted 26 May, Published 20 July 2021
}

\begin{abstract}
The usage of the low-cost catalysts for methylene blue removal from wastewater was investigated. Heterogeneous Fenton-like process consists of the use of a hydrogen peroxide solution, and an iron-rich catalyst, red mud and black nickel mud were used for that purpose. The factors such as the catalyst dose and the hydrogen peroxide solution volume were monitored. The results of experiments showed that the degradation of methylene blue dye in Fenton-like oxidation process using selected catalysts can be described by a pseudo-secondorder kinetic model. The highest dye removal efficiency (87.15\%) was achieved using the black nickel mud catalyst after 30 minutes of reaction.
\end{abstract}

\section{Keywords}

Fenton-like process, red mud, black nickel mud, methylene blue

\section{INTRODUCTION}

In recent years, the rapid development of textiles, food, cosmetics, and printing industries has led to an increase in the highly toxic and carcinogenic pollutants from organic dyes in wastewaters $[1,2]$. It was reported that the effluents from textile industries typically contain 0.6- $0.8 \mathrm{~g} \mathrm{~L}^{-1}$ of dye [3]. Dyes are chemicals which consist of aromatic structures; without proper wastewater treatment, they can be harmful to the aquatic environment and human health [4]. The molecules of dyes may shield light penetration in watercourses and affect the photosynthesis of aquatic plants [2]. Methylene blue (MB) can stimulate and injure the eyes of 
humans and animals. Eating food contaminated with MB results in nausea, vomiting, profuse sweating, mental confusion and methemoglobinemia [5-7].

There are several decolorization methods applicable for the regeneration of dyed wastewaters. Common treatment methods consist of various processes involving the biological, physical, and chemical methods, but biological treatment is not preferred owing to biological resistance of some dyes [8,9]. Traditional treatment techniques include ion-exchange, coagulation/flocculation, microelectrolysis, advanced oxidation processes, adsorption, membrane filtration, photocatalysis and various combinations of these methods. The advantages and disadvantages of every removal technique have been reviewed [10].

Homogeneous Fenton process is an effective treatment technique to degrade organic pollutants by generation of strong, relatively non-selective hydroxyl radical $\left({ }^{\circ} \mathrm{OH}\right)[11,12]$. However, secondary contamination and difficulty in recycling the catalyst is the main problem in application of Fenton in the industrial scale in wastewater treatment [13, 14]. This problem can be solved by using a heterogeneous catalyst in Fenton process, because it is usually environmentally more acceptable and easily separable from treated wastewater $[15,16]$. Heterogeneous catalysts are divided into the catalysts from natural minerals and the ones from composites by artificial synthesis [17]. Iron-rich waste can be served as a raw material for the preparation of heterogeneous catalysts, but it is very important to develop a low-cost, green, and efficient method for its preparation [18].

Red mud (RM) is alkaline solid waste from alumina production. Normally, it consists of $\mathrm{Fe}_{2} \mathrm{O}_{3}, \mathrm{SiO}_{2}, \mathrm{Al}_{2} \mathrm{O}_{3}, \mathrm{TiO}_{2}, \mathrm{Na}_{2} \mathrm{O}, \mathrm{CaO}, \alpha-\mathrm{FeOOH}, \gamma-\mathrm{AlOOH}$, etc. [19]. Yearly production of red mud in Slovakia was about $7 \times 10^{4} \mathrm{~kg}$, and supplies are estimated at 8 million tons [20].

Black nickel mud (BNM) is a waste generated during the leaching of nickel and cobalt from lateritic iron-ore. Chemical composition of black nickel mud is $\mathrm{Fe}, \mathrm{Cr}_{2} \mathrm{O}_{3}, \mathrm{SiO}_{2}, \mathrm{Al}_{2} \mathrm{O}_{3}$, $\mathrm{CaO}, \mathrm{Ni}$, and $\mathrm{P}_{2} \mathrm{O}_{3}$ [21]. In Slovakia, nickel was produced in the southern edge of Dolnovažská niva. Annual production of BNM was about $3 \times 10^{5} \mathrm{~kg}$, and supplies in Slovakia are estimated at 5.6 million tons $[21,22]$.

In the experiment described in this article, the red mud and black nickel mud were used as catalysts for removal of the methylene blue water solution using Fenton-like process. The study focuses on usage of low-cost industrial waste for wastewater treatment. The factors such as catalyst dosage and volume of the hydrogen peroxide solution were studied. The efficiency of removal process was calculated, and degradation kinetics $\left(\mathrm{C} / \mathrm{C}_{0}\right.$ versus time plots $)$ are shown. Kinetic study of the reactions was also performed.

\section{MATERIALS AND METHODS}

\section{Chemicals and catalysts}

Methylene blue was dissolved in distilled water to reach a $10 \mathrm{mg} \mathrm{L}^{-1}$ concentration of solution. The hydrogen peroxide (HP) solution was prepared at a concentration of $30 \% \mathrm{w} / \mathrm{v}$. RM - industry waste from metal production was supplied from Žiar nad Hronom, which was produced in an aluminium mill from bauxite between the years 1957-1997. BNM - industry waste from metal production, supplied from the area between Sered' and Dolná Streda, which was produced by leaching of nickel and cobalt from lateritic iron-ore in Niklová huta š.p (19631993). Soldán and Kobetičová (2015) investigated the chemical composition and surface morphology of those catalysts using the SEM and EDX analyses [20]. 


\section{Experimental procedure}

A sample of $25 \mathrm{~mL}$ of methylene blue solution $\left(10 \mathrm{mg} \mathrm{L}^{-1}\right)$ was pipetted into the beaker. Then 0.1 and $0.2 \mathrm{~g}$ of red mud and black nickel mud were added separately. Finally, 0.5 and 1 $\mathrm{ml}$ of $\mathrm{H}_{2} \mathrm{O}_{2}(30 \% \mathrm{w} / \mathrm{v})$ were added. The suspension was then stirred by a glass rod for a few seconds at the beginning. The reaction was run for 5, 10, 15 and 30 minutes. After time, the suspension was transferred to a test tube and centrifuged in Nahita centrifuge (model 2640/12) for 3 minutes at $4000 \mathrm{rpm}$. The MB removal efficiency was determined by the UV/Vis spectroscopy. All experiments were performed at the room temperature.

\section{UV/Vis spectroscopy}

The degradation of MB was determined by the GENESYS 8 spectrophotometer in UV/Vis area $(500-800 \mathrm{~nm})$. Plastic cuvettes $1 \mathrm{~cm}$ thick were used. The highest achieved value of absorbance (at $665 \mathrm{~nm}$ ) was used to calculate the efficiency of removal process.

\section{RESULTS AND DISCUSSION}

\section{Removal of MB using RM as a catalyst}

Figure 1 shows the monitored degradation kinetics of MB using Fenton-like process with red mud. For comparison, the degradation kinetics of individual experiments with hydrogen peroxide solution and RM are also given.

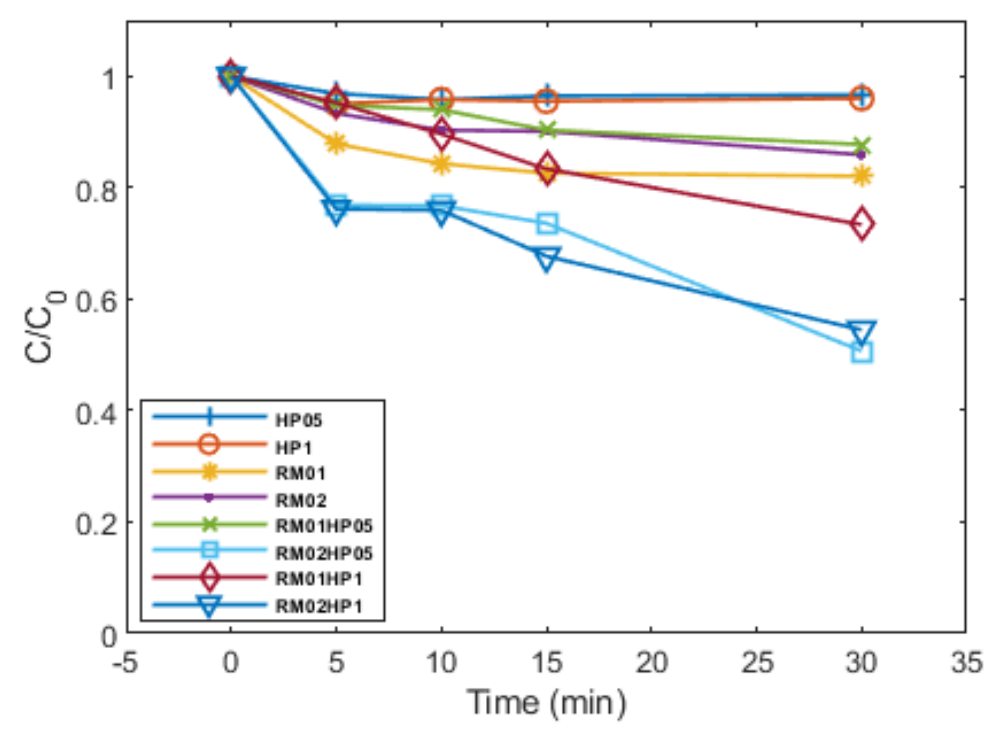

Figure 1 Comparison of degradation kinetics of $M B$ removal using $R M$ as catalyst

Figure 1 also shows that a higher volume of hydrogen peroxide solution used in this case does not have a significant effect on the resulting removal efficiency. Although the reactions were initially copied using $0.2 \mathrm{~g}$ of RM, 0.5 and $1 \mathrm{ml}$, the RM02HP05 reaction ultimately reached its highest efficiency $(49.34 \%)$ after 30 minutes. 


\section{Removal of MB using BNM as a catalyst}

Degradation kinetics of MB using BNM as a catalyst for Fenton-like process are shown in Figure 2. For comparison, the degradation kinetics of individual experiments with HP solution and $\mathrm{BNM}$ are also given.

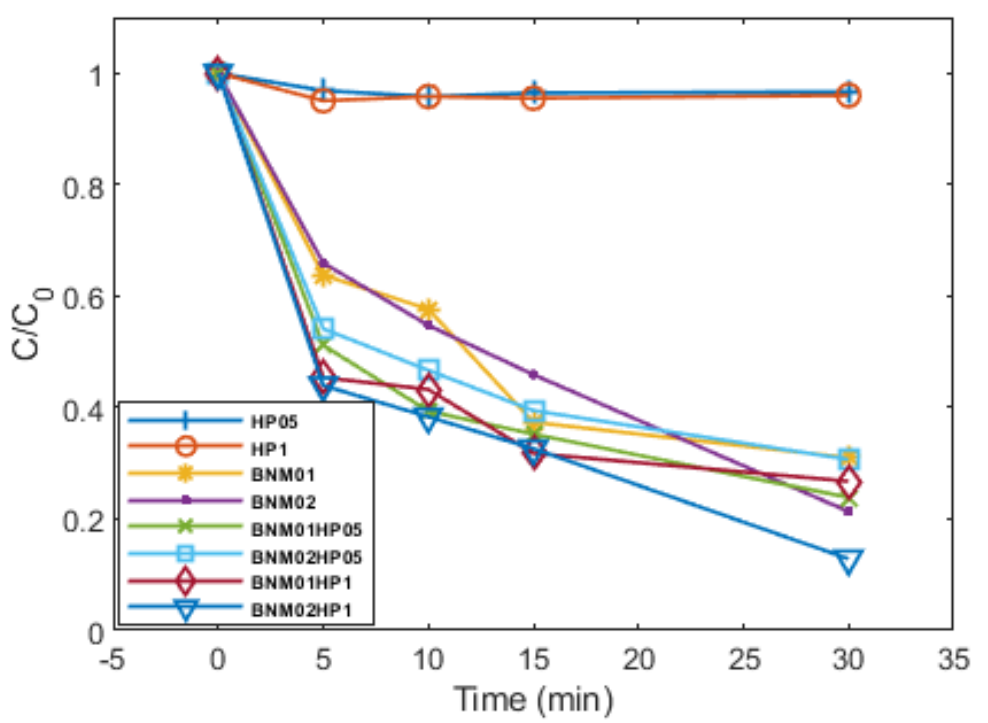

Figure 2 Comparison of degradation kinetics of $M B$ removal using BNM as catalyst

The highest removal efficiency of MB from all experiments performed can be seen in Figure 2. using $0.2 \mathrm{~g}$ of BNM and $1 \mathrm{~mL}$ of hydrogen peroxide solution; $87.15 \%$ of dye solution was removed after 30 minutes.

\section{Kinetics of MB removal}

The kinetic study of Fenton-like process can be performed by assuming that the reaction between hydroxyl radicals and the pollutant is the rate-determining step. Thus, by assuming that hydroxyl radical concentration was a constant, the law of pseudo-first-order reaction can be written as follows:

$$
-\frac{d \mathrm{C}}{d \mathrm{t}}=k \times C_{{ }_{\mathrm{OH}}} \times C=k_{\mathrm{app}} \times C \Rightarrow \ln \frac{C_{0}}{C}=k_{\text {app }} \times \mathrm{t}
$$

where $C$ and $C_{0}$ are concentrations of $\mathrm{MB}$ at any time and initial $\mathrm{MB}$ concentration in $\mathrm{mg} \mathrm{L}^{-1}, k$ is the rate constant of reaction, and $\mathrm{k}_{\mathrm{app}}$ is the apparent pseudo-first-order constant.

Table 1 shows the kinetic parameters (rate constant $k$ and coefficient of linear regression $R^{2}$ ) of selected reactions. Rate law of the pseudo-second-order reaction can be written as follows:

$$
\frac{1}{C_{\mathrm{MB}}}=k \times t+\frac{1}{C_{0}} .
$$




\begin{tabular}{|l|l|c|c|}
\hline \multicolumn{4}{|l|}{ Table 1 Parameters of kinetic models for different catalysts in Fenton-like process } \\
\hline Kinetic type & Reaction & $\boldsymbol{k}$ & $\boldsymbol{R}^{\mathbf{2}}$ \\
\hline \multirow{2}{*}{ Pseudo-first-order } & RM02HP1 & 0.0182 & 0.91 \\
\cline { 2 - 4 } & BNM02HP1 & 0.0615 & 0.93 \\
\hline \multirow{2}{*}{ Pseudo-second-order } & RM02HP1 & 0.0026 & 0.95 \\
\cline { 2 - 4 } & BNM02HP1 & 0.0219 & 0.94 \\
\hline
\end{tabular}

From Table 1, it can be read that the coefficient of linear regression $\left(R^{2}\right)$ acquires the highest values for the pseudo-second-order kinetic type. Figure 3 shows the pseudo-secondorder models of MB degradation with different catalysts.

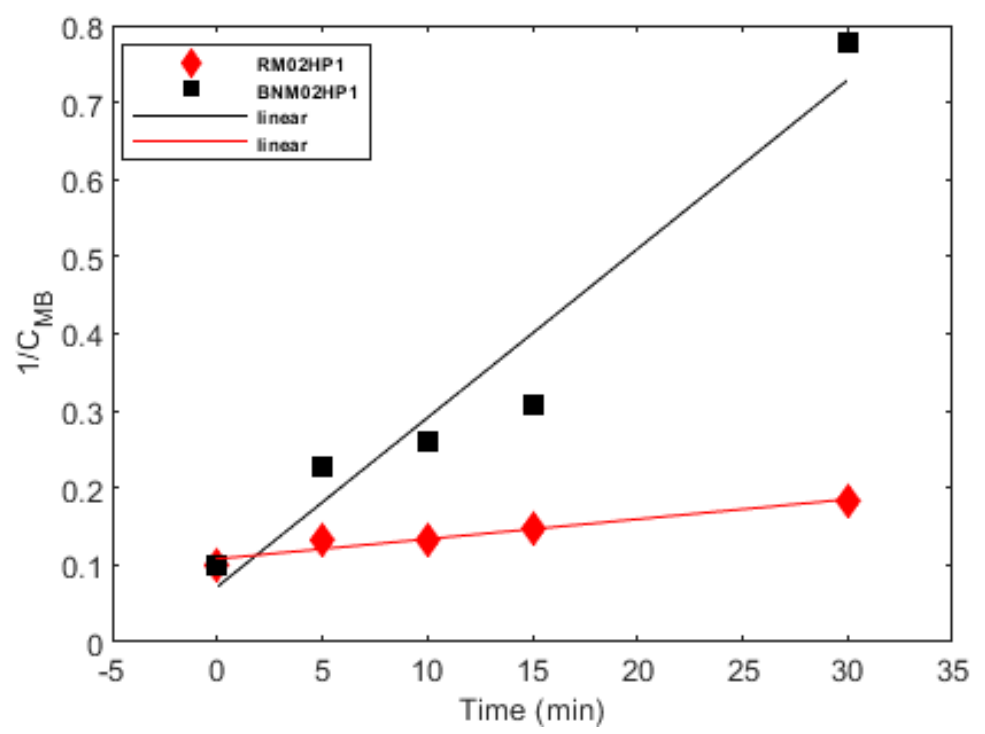

Figure 3 Pseudo-second-order models for Fenton-like oxidation of MB with different catalysts

\section{CONCLUSION}

The results stated above show the efficiency of MB removal using red mud and black nickel mud as catalysts. Time of the reaction, catalysts dosage and volume of hydrogen peroxide solution are important factors, because they affect the cost and simplicity of the process.

Removal of methylene blue using the Fenton-like process with RM catalyst achieved the highest efficiency of $49.34 \%$ using $0.2 \mathrm{~g}$ of catalyst and $0.5 \mathrm{ml}$ of HP solution. Given that the reaction using a $1 \mathrm{ml}$ volume of HP solution ultimately had less than $6 \%$ lower efficiency, we can conclude that these reactions were identical, and the volume of HP solution did not affect the resulting MB removal efficiency. This could also be because the slurry was stirred for only a few seconds at the beginning of the reaction, which resulted in an inefficient use of the entire catalyst surface with hydrogen peroxide.

The highest MB removal efficiency was achieved using black nickel mud as a catalyst. Using $0.2 \mathrm{~g}$ of BNM and $1 \mathrm{ml}$ of HP solution, $87.15 \%$ dye removal was achieved after 30 minutes.

It can be concluded that BNM was proven to be a more effective catalyst for the removal of MB in the Fenton-like oxidation process than RM. Based on these facts, it should be noted that in future research, it would be appropriate to monitor possible secondary pollution and other factors, such as the effect of $\mathrm{pH}$, the effect of temperature, the effect of catalyst pretreatment, etc. 


\section{Acknowledgement}

This research was funded by the Slovak Research and Development Agency under the contract No. APVV-16-0223 and by the STU Grant scheme for Support of Young Researchers.

\section{References}

[1] HUANG, Y. et al. 2020. Acrylic acid grafted-multi-walled carbon nanotubes and their highefficiency adsorption of methylene blue. Journal of Materials Science, 55, 4656-4670. ISSN 15734803.

[2] WANG, F., YEAP, S.P. 2021. Using magneto-adsorbent for methylene Blue removal: A decisionmaking via analytical hierarchy process (AHP). Journal of Water Process Engineering, 40, 101948. ISSN 2214-7144.

[3] UPENDAR, G. et al. 2017. Adsorptive removal of methylene blue dye from simulated wastewater using shale: Experiment and modelling. Journal of the Indian Chemical Society, 94, 971-982. ISSN: 0019-4522.

[4] ARAYAPHAN, J. et al. 2021. Synthesis of photodegradable cassava starch-based double network hydrogel with high mechanical stability for effective removal of methylene blue. International Journal of Biological Macromolecules, 168, 875-886. ISSN 0141-8130.

[5] VAN, H.T. et al. 2018. Applying activated carbon derived from coconut shell loaded by silver nanoparticles to remove methylene blue in aqueous solution. Water Air Soil Pollution, 229(12), 393. ISSN 1573-2932.

[6] TAN, I.A.W. et al. 2008. Adsorption of basic dye on high-surface-area activated carbon prepared from coconut husk: equilibrium, kinetic and thermodynamic studies. Journal of Hazardous Materials, 154(1-3), 337-346. ISSN 0304-3894.

[7] TAN, I.A.W. et al. 2008. Adsorption of basic dye using activated carbon prepared from oil palm shell: batch and fixed bed studies. Desalination, 225(1-3), 13-28. ISSN 0011-9164.

[8] PIERCE, J. 1994. Colour in textile effluents - the origins of the problem. Journal of the Society of Dyers and Colourists, 110(4), 131-133. ISSN 1478-4408.

[9] GALINDO, C. et al. 2001. Photochemical and photocatalytic degradation of an indigoid dye: a case study of acid blue 74 (AB74), Journal of Photochemistry and Photobiology A, 141(1), 47-56. ISSN 1010-6030.

[10] SALLEH, M.A.M. et al. 2011. Cationic and anionic dye adsorption by agricultural solid wastes: a comprehensive review. Desalination, 280(1-3), 1-13. ISSN 0011-9164.

[11] HE, R. et al. 2015. Effect of Fenton oxidation on biodegradability, biotoxicity and dissolved organic matter distribution of concentrated landfill leachate derived from a membrane process. Waste Management, 38, 232-239. ISSN 0956-053X.

[12] AMIRI, A., SABOUR, M.R. 2014. Multi-response optimization of Fenton process for applicability assessment in landfill leachate treatment. Waste Management, 34, 2528-2536. ISSN 0956-053X.

[13] KUANG, Y. et al. 2013. Heterogeneous Fenton-like oxidation of monochlorobenzene using green synthesis of iron nanoparticles. Journal of Colloid and Interface Science, 410, 67-73. ISSN 00219797.

[14] ZHANG, Y. et al. 2011. A coupling process of membrane separation and heterogeneous Fentonlike catalytic oxidation for treatment of acid orange II-containing wastewater. Separation and Purification Technology, 80(1), 45-51. ISSN 1383-5866.

[15] WANG, X.F. et al. 2014. Efficient degradation of rhodamine B using Fe-based metallic glass catalyst by Fenton-like process. Chemosphere, 117, 638-643. ISSN 0045-6535.

[16] LI, B.Z., ZHU, J. 2014. Removal of p-chloronitrobenzene from groundwater: Effectiveness and degradation mechanism of a heterogeneous nanoparticulate zero-valent iron (NZVI)-induced Fenton process. Chemical Engineering Journal, 225, 225-232. ISSN 1385-8947.

[17] WANG, N.N. et al. 2016. A review on Fenton-like processes for organic wastewater treatment. Journal of Environmental Chemical Engineering, 4(1), 762-787. ISSN 2213-3437.

[18] WEI, G.T. et al. 2017. Preparation of a new Fenton-like catalyst from red mud using molasses wastewater as partial acidifying agent. Environmental Science and Pollution Research, 24, 1506715077. ISSN 1614-7499. 
[19] WANG, Y.Z., et al. 2016. Preparation of a low-cost adsorption material from red mud and bagasse. Materials and Manufacturing Processes, 31(2), 162-167. ISSN 1532-2475.

[20] SOLDÁN, M., KOBETIČOVÁ, H. 2015. The structure of hazardous industrial wastes. International Journal of Current Research, 7(12), 24119-24122. ISSN 0975-833X.

[21] MICHAELI, E. et al. 2012. The Landfill of Industrial Waste - lúženec near the former Nickel Smelter at Sered' Town as an Example of Environmental Load. Životné prostredie, 46(2), 63-68. ISSN 2585-7800.

[22] SOLDÁN, M. et al. 2013. Evaluation of the structure of industrial wastes. Advanced Materials Research, (664), 185-190. ISSN 1662-8985.

\section{ORCID}

Juraj Michálek 0000-0002-4775-1210

Maroš Soldán 0000-0003-1520-1051 